\title{
SIMPLE METHOD OF PREDICTING FRICTION FACTORS OF TURBULENT FLOW IN NON-CIRCULAR CHANNELS
}

\author{
K. REHME \\ Institut für Neutronenphysik: und Reaktortechnik, Karlsruhe Nuclear Research Centre, D-7500 Karlsruhe 1, \\ P.O. Box 3640, Germany
}

(Received 17 July 1972)

\begin{abstract}
On the basis of friction factor relationships of a simple model a method is developed which allows the prediction of friction factors for turbulent flow in non-circular channels if only the geometry factor of the pressure drop relationship for laminar flow is known. The proposed method of calculation is tested with numerous experimental results from the literature with respect to non-circular channels such as triangular shaped ducts, eccentric annuli and rod bundles in hexagonal and square arrays in circular tubes, hexagonal and square channels. It turns out that the proposed method provides an excellent description of all the experimental data at hand.
\end{abstract}

\section{NOMENCLATURE}

A, geometry factor;

$D$, rod and tube diameter, respectively;

$D_{h}$, hydraulic diameter;

$F, \quad$ flow cross section;

G, geometry factor (turbulent flow);

$G^{*}, \quad$ geometry factor (turbulent flow);

$K, \quad$ geometry factor (laminar flow);

$K_{R}, \quad$ geometry factor for circular tube;

$K_{R Z}$, geometry factor for annular zone;

$L, \quad$ characteristic length;

$l, \quad$ length in flow direction;

$P, \quad$ distance between rod centres;

$p$, pressure;

$r$ radius;

$\left.\begin{array}{l}r_{0}, \\ r_{z},\end{array}\right\}$ radii of annular zone;

$U, \quad$ velocity;

$U_{m}$, velocity averaged over the cross section $F$;

$U_{\max }, \quad$ maximum velocity;

$U^{*}, \quad$ friction velocity $U^{*}=\sqrt{ }(\tau w / \rho)$;

$U^{+}, \quad$ dimensionless velocity $U^{+}=U / U^{*}$;

$W$, wall distance in rod bundles $=\operatorname{rod}$ diameter + closest distance between channel wall and rods;

$x$, annular zone parameter;

$Y$ wall distance;

$Y^{+}, \quad$ dimensionless wall distance $Y^{+}=$ $Y U^{*} / v$;

$\lambda$, friction factor;

$\lambda_{R}, \quad$ friction factor of the circular tube;

$\rho, \quad$ density;

$\tau_{w}, \quad$ wall shear stress;

$v$, kinematic viscosity.

\section{INTRODUCTION}

RESULTS of pressure drop measurements have been known for a number of years for turbulent flow in various non-circular channels which cannot be described in terms of the friction factors of the circular tube when using the hydraulic diameter as the characteristic length. Noncircular tubes, i.e. rod bundles, are used especially in reactor technology.

Both in theoretical and experimental studies of the friction factors of rod bundles the strong influence of the type and arrangement of channel wall upon the friction factor was soon discovered, however, without there being a general 
solution to the dependence on geometry of the friction factors.

Below, a method is developed and tested for various non-circular channels by means of numerous measured results which allows the friction factor for turbulent flow to be indicated in a simple way. The only condition on which the method can be applied is the required knowledge of the geometry factor of laminar flow. However, geometry factors of laminar flow are known for a variety of non-circular channels or else can be determined quickly and rather accurately by numerical calculation procedures.

A few methods are mentioned in the literature which can be used to calculate the friction factor for turbulent flow on the basis of laminar solutions [1-4]. These methods will not be mentioned in more detail in this paper because the method outlined here is basically different and refers only to the geometry factors of the pressure drop relationships. For this purpose, the geometry factors will be explained very briefly.

\section{GEOMETRY FACTORS OF THE PRESSURE DROP RELATIONSHIPS}

The pressure drop relationship for laminar flow is

$$
\lambda R e=K
$$

where the constant $K$ is a geometry factor, because it is determined solely by the geometry. It is the eigenvalue of Poisson's equation.

For turbulent flow there is also a geometry factor, as has been proved by Maubach [5] for circular tubes, annular zones, and parallel plates. This geometry factor $G$ of turbulent flow turns out to be

$$
G=\frac{U_{\max }-U_{m}}{U^{*}}
$$

with the maximum velocity $U_{\text {max }}$, the velocity averaged over the flow cross section $U_{m}$ and the friction velocity $U^{*}=\sqrt{ }\left(\tau_{w} / \rho\right)$.

Maubach was able to show that this geometry parameter $G$ has a characteristic value for each shape of channel, which value is independent of, for instance, the roughness of the channel or the Reynolds number, if, in case of small Reynolds numbers, the factor is left out of account that the sublayer close to the wall gives rise to a minor correction.

Of course, this geometry parameter occurs also in the pressure drop relationships of the geometries studied by Maubach. Under the condition of a universal velocity profile existing for the channels investigated, such as Nikuradse's profile,

$$
u^{+}=2.5 \ln y^{+}+5.5
$$

the pressure drop relationships are written as follows [5]:

$$
\sqrt{\left(\frac{8}{\lambda}\right)}=2 \cdot 5 \ln \frac{L U^{*}}{v}+5 \cdot 5-G
$$

where $L$ is the length characterizing the flow cross section, which is the thickness of the flow layer in the geometries studied by Maubach.

As is evident, the following questions arise in the light of these facts :

(1) Can a relationship be established between the two geometry parameters $K$ and $G$ for laminar and turbulent flow, respectively?

(2) What must be the structure of the pressure drop relationships for channels with the wall shear stress variable on the circumference in order to fully take into account both experimental and theoretical results?

\section{MULTICHANNEL EFFECT}

For more detailed studies of the pressure drop behaviour of channels with wall shear stresses variable on the circumference it is necessary to visualize the characteristics of such channels. One characteristic all these channels have in common is a different curvature of the walls either, as in the case of annuli, there are different radii of curvature of the walls or, as in triangular shaped ducts, discontinuities in the curvature of the wall in the corners. Now, it has been proved in a large number of experiments that the velocity profile obviously is not influenced by 
the curvature of the wall [7-11]. Results obtained on annuli by Brighton and Jones [12] showing a dependence of the velocity profile on the curvature of the wall do not agree with measurements by Quarmby [18]. Quarmby concludes that the results by Brighton and Jones are wrong. However, we believe the results by Brighton and Jones have been misinterpreted because of the assumption that the line of maximum velocity was identical with the line of zero shear stress [14], which results in a dependence on wall curvature of the velocity profile in the results of Brighton and Jones.

Another characteristic of the channels with a wall shear stress variable on the circumference is the existence of zero shear stress lines in the flow area. Such flow channels can be subdivided along these lines because, averaged over time, there is no momentum transport across these lines. Such subdivision gives rise to parallel subchannels which are independent of each other. Since these subchannels in general have different flow cross sections and wall fractions, the way in which the individual parallel channels interact and the relationships that can be derived from such interaction must be investigated.

\section{Parallel circular tubes}

These relationships will be derived by a simple example which can be described unambiguously in terms of the solutions available. For this purpose, the model of parallel circular tubes suggested by Maubach will be used.

We look for the friction factor of a number of smooth, parallel connected circular tubes of various diameters with inner flow, that is a flow channel with several sub-channels.

An incompressible, isothermal, fully developed turbulent flow is assumed. In addition, the tubes are assumed to be long enough to make the inlet and outlet losses small relative to the friction pressure drop. Hence, it applies for all the parallel channels that

$$
\frac{\partial p_{i}}{\partial l}=\text { const. }
$$

where $p_{i}$ is the pressure in the $i$ th channel of the diameter $D_{i}$.

Now, according to Maubach [5], the following friction law (4) applies for smooth circular tubes with $L=D_{i} / 2$ and

$$
U^{*}=U_{m} \sqrt{\left(\frac{\lambda}{8}\right)}
$$

$$
\sqrt{\left(\frac{8}{\lambda_{i}}\right)}=2 \cdot 5 \ln \left[\frac{D_{i}}{2} \frac{U_{i}}{v} /\left(\frac{\lambda_{i}}{8}\right)\right]+5 \cdot 5-G_{i}
$$

with the geometry parameter for Reynolds numbers $R e<10^{6}$

$$
G_{i}=U_{\max }^{+}-U_{m}^{+}=3 \cdot 966 .
$$

The equation defining the friction factor

$$
\frac{\partial p}{\partial l}=\lambda \frac{\rho}{2} U_{m}^{2} \frac{1}{D_{h}}
$$

and (5) result in

$$
\frac{\lambda_{i} U_{i}^{2}}{D_{i}}=\text { const. }=\frac{\lambda U_{m}^{2}}{D_{h}} .
$$

Finally, the continuity equation furnishes

$$
\sum_{i=1}^{n} \frac{U_{i}}{U_{m}} \frac{F_{i}}{F}=1
$$

From (10) it is found that

$$
\frac{U_{i}}{U_{m}}=\sqrt{ }\left(\frac{D_{i}}{D_{h}}\right) \sqrt{ }\left(\frac{\lambda}{\lambda_{i}}\right)
$$

which turns (11) into

$$
\sum_{i=1}^{n} \sqrt{\left(\frac{D_{i}}{D_{h}}\right)^{F_{i}}} \sqrt{\left(\frac{\lambda}{\lambda_{i}}\right)=1}
$$

or

$$
\sqrt{\left(\frac{8}{\lambda}\right)}=\sum_{i=1}^{n} \sqrt{ }\left(\frac{8}{\lambda_{i}}\right) \sqrt{ }\left(\frac{D_{i}}{D_{h}}\right) \frac{F_{i}}{F}
$$

In this way the wanted friction factor $\lambda$ of the entire channel has been found. 
From (7) it follows with (12)

$$
\begin{aligned}
& \sqrt{\left(\frac{8}{\lambda_{i}}\right)}=2.5 \ln \left[\frac{D_{i}}{2} \frac{1}{v} \sqrt{\left(\frac{\lambda_{i}}{8}\right)}\right. \\
& \left.\quad \times U_{m} \sqrt{\left(\frac{D_{i}}{D_{h}}\right)} \sqrt{ }\left(\frac{\lambda}{\lambda_{i}}\right)\right]+5.5-G_{i}
\end{aligned}
$$

$$
\begin{aligned}
& \text { or } \\
\sqrt{\left(\frac{8}{\lambda_{i}}\right)}=2.5 \ln \left[\operatorname{Re} \sqrt{\left(\frac{\lambda}{8}\right)}\right. & \left.\frac{1}{2}\left(\frac{D_{i}}{D_{h}}\right)^{\frac{3}{2}}\right] \\
& +5.5-G_{i} .
\end{aligned}
$$

Substituting (16) in (14) yields

$$
\begin{aligned}
& \sqrt{\left(\frac{8}{\lambda}\right)}=\sum_{i=1}^{n} \sqrt{\left(\frac{D_{i}}{D_{h}}\right) \frac{F_{i}}{F}} \\
& \times\left\{2 \cdot 5 \operatorname { l n } \left[\operatorname{Re} \sqrt{\left.\left.\left(\frac{\lambda}{8}\right) \frac{1}{2}\left(\frac{D_{i}}{D_{h}}\right)^{\frac{3}{2}}\right]+5 \cdot 5-G_{i}\right\}} .\right.\right.
\end{aligned}
$$

Now, the pressure drop relationship of the entire channel can be written as

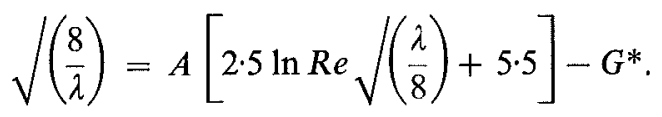

A comparison of coefficients makes (17) and (18) into

$$
\begin{aligned}
A=\sum_{i=1}^{n} \sqrt{\left(\frac{D_{i}}{D_{h}}\right) \frac{F_{i}}{F}} \\
G^{*}=-\sum_{i=1}^{n}\left[2 \cdot 5 \ln \frac{1}{2} \frac{D_{i}}{D_{h}} /\left(\frac{D_{i}}{D_{h}}\right)-G_{i}\right] \\
\times \sqrt{\left(\frac{D_{i}}{D_{h}}\right) \frac{F_{i}}{F}}
\end{aligned}
$$

with the entire area

$$
F=\sum_{i=1}^{n} F_{i}
$$

and the hydraulic diameter of the entire channel

$$
D_{h}=\frac{4 \sum_{i=1}^{n} F_{i}}{\sum_{i=1}^{n} P_{i}} .
$$

Since the quantities of $A$ and $G^{*}$ defined in (19) and (20) depend only on the diameter and area relationships and the geometry parameter $G_{i}$, $A$ and $G^{*}$ are two new geometry parameters which are independent of the flow condition, i.e. the Reynolds number.

For laminar flow in the sub-channels it applies for each tube that

$$
\lambda_{i}=\frac{64}{R e_{i}}
$$

and for the entire channel

$$
\lambda=\frac{K_{\text {ges }}}{R e} .
$$

The continuity equation (11) and (10) can be used to find for the geometry factor of the entire channel in the case of laminar flow

$$
K_{\mathrm{ges}}=\frac{64}{\sum_{i=1}^{n}\left(\frac{D_{i}}{D_{h}}\right)^{2} \frac{F_{i}}{F}} .
$$

For calculation of the friction factors for laminar and turbulent flow it is assumed that a tube of the diameter $D_{1}$ with $n$ tubes of the diameter $D_{2}$ make up a channel. Hence, the channel is determined by $D_{2} / D_{1}$ and $n$.

Table 1 is a compilation of the $K_{\text {ges }}, A$ and $G^{*}$ determined for various parameters investigated. Moreover, the friction coefficient referred to the circular tube value is indicated for $R e=10^{4}$ and $R e=10^{5}$.

In Figs. 1 and 2, the relative friction factors are plotted over the diameter ratio with the number of parallel tubes as a parameter for laminar and turbulent flow, respectively. It is 
Table 1. Results for parallel circular tubes $(\mathrm{G}=3.966)$

\begin{tabular}{|c|c|c|c|c|c|}
\hline$d_{1} / d_{2}$ & 0.05 & 0.01 & $0 \cdot 3$ & $0 \cdot 5$ & $0 \cdot 9$ \\
\hline \multicolumn{6}{|l|}{$n=1$} \\
\hline$K_{\mathrm{ges}}$ & $58 \cdot 59$ & $54 \cdot 49$ & $48 \cdot 65$ & $52 \cdot 29$ & $63 \cdot 48$ \\
\hline$A$ & $1 \cdot 021$ & 1.037 & $1 \cdot 051$ & $1 \cdot 031$ & $1 \cdot 001$ \\
\hline$G^{*}$ & $5 \cdot 650$ & 5.603 & $5 \cdot 520$ & 5.575 & $5 \cdot 694$ \\
\hline$\lambda / \lambda_{R} \quad R e=10^{4}$ & 0.947 & 0.911 & 0.874 & 0.919 & 0.997 \\
\hline $\begin{array}{l}\lambda / \lambda_{R} R e=10^{5} \\
n=2\end{array}$ & 0.950 & 0.915 & 0.881 & 0.923 & 0.998 \\
\hline$K_{\text {ges }}$ & $53 \cdot 69$ & $47 \cdot 16$ & $40 \cdot 42$ & $48 \cdot 00$ & $63 \cdot 50$ \\
\hline$A$ & 1.042 & 1.070 & $1 \cdot 084$ & 1.042 & 1.001 \\
\hline$G^{*}$ & 5.599 & $5 \cdot 504$ & $5 \cdot 380$ & $5 \cdot 521$ & $5 \cdot 695$ \\
\hline$\lambda / \lambda_{R} \quad R e=10^{4}$ & 0.899 & 0.838 & $0 \cdot 804$ & 0.892 & 0.998 \\
\hline $\begin{array}{l}\lambda / \lambda_{R} R e=10^{5} \\
n=5\end{array}$ & $0 \cdot 904$ & 0.846 & $0 \cdot 814$ & $0 \cdot 898$ & 0.998 \\
\hline$K_{\text {ges }}$ & $42 \cdot 51$ & 32.91 & $30 \cdot 00$ & $45 \cdot 34$ & $63 \cdot 66$ \\
\hline$A^{\circ+0}$ & $1 \cdot 101$ & $1 \cdot 156$ & $1 \cdot 129$ & $1 \cdot 044$ & $1 \cdot 001$ \\
\hline$G^{*}$ & $5 \cdot 436$ & $5 \cdot 198$ & $5 \cdot 135$ & $5 \cdot 494$ & $5 \cdot 696$ \\
\hline$\lambda / \lambda_{R} \quad R e=10^{4}$ & 0.781 & 0.684 & $0 \cdot 717$ & 0.885 & 0.998 \\
\hline $\begin{array}{l}\lambda / \lambda_{R} \quad R e=10^{5} \\
n=10\end{array}$ & 0.791 & 0.697 & $0 \cdot 731$ & 0.892 & 0.999 \\
\hline$K_{\text {ges }}$ & $30 \cdot 63$ & $21 \cdot 27$ & $25 \cdot 38$ & $46 \cdot 91$ & $63 \cdot 78$ \\
\hline$A^{B+0}$ & $1 \cdot 187$ & $1 \cdot 265$ & $1 \cdot 140$ & 1.035 & $1 \cdot 000$ \\
\hline$G^{*}$ & 5.143 & $4 \cdot 706$ & 5.014 & $5 \cdot 527$ & 5.697 \\
\hline$\lambda / \lambda_{R} \quad R e=10^{4}$ & 0.643 & 0.540 & 0.694 & 0.906 & 0.999 \\
\hline$\lambda / \lambda_{R} \quad R e=10^{5}$ & 0.657 & 0.557 & 0.709 & 0.912 & 0.999 \\
\hline
\end{tabular}

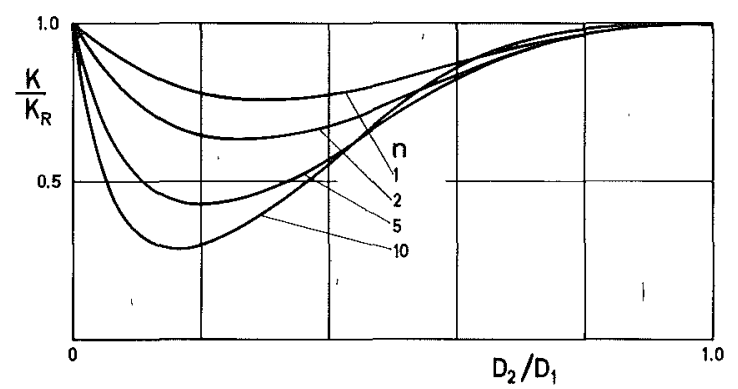

FIG. 1. Tubes in parallel: laminar flow.

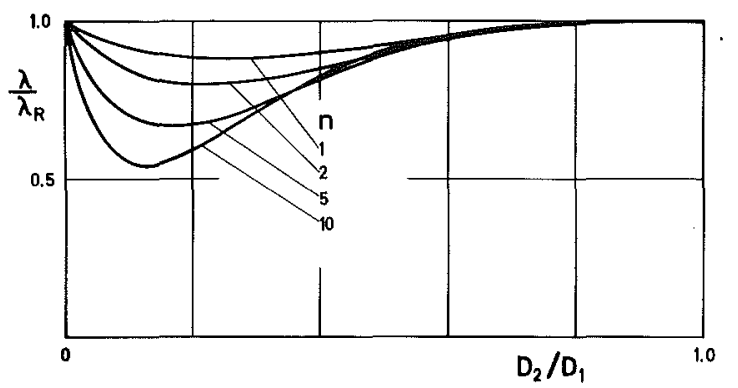

FIG. 2. Tubes in parallel: turbulent flow. evident that the friction factor is decreased with irregular flow distribution. Depending upon the number of tubes the minimum of the overall friction factor is shifted towards the other $D_{2} / D_{1}$. For a large number of tubes the friction factor is decreased significantly below the value of the single tube. This behaviour is typical of friction factors in the case of parallel connection of channels of different cross sections and shapes of cross sections. The effect is called the multichannel effect.

\section{NEW METHOD OF CALCULATING FRICTION FACTORS}

A comparison of Figs. 1 and 2 clearly indicates that the friction factor in turbulent and laminar flows show a similar behaviour. In laminar flow, the dependencies are more marked than in turbulent flow, but the basic shape of curves is the same. The same results are found by comparing the measured results obtained from triangular shaped ducts, eccentric annuli, and rod bundles for laminar and turbulent flows. It turns out that if, for a specific geometry, the friction factor for laminar flow drops below the circular tube value, also the friction factors for turbulent flow are lower than the circular tube values, and vice versa.

If this effect can be ascribed mainly to the geometry factors of the pressure drop relationships, it must be possible to establish a relationship between the geometry factors. Since, in laminar flow, only one geometry factor $K$ is needed to describe the pressure drop relationships, whereas it takes two, namely $A$ and $G^{*}$, in the case of turbulent flow, as we have seen, the geometry factors $A$ and $G^{*}$ are plotted over $K$.

Figure 3 is a plot of the magnitudes of $G^{*}$ obtained from the multi-tube model. It appears that for $K>20$ the points can be arranged on a curve with only a small amount of scatter. Geometries so far investigated experimentally and applied in practice always have values in excess of $K=20$. For geometry factors $K>64$, the respective $G^{*}$ values were determined from the annular zone solution. In this case, the 
laminar solution of the annular zone turns out to be [15]

$$
K_{R Z}=\frac{64\left(x^{2}-1\right)^{3}}{3 x^{4}-4 x^{2}-4 x^{2} \ln x+1}
$$

with the annular zone parameter (cf. Fig. 4)

$$
x=\frac{r_{0}}{r_{z}} .
$$

The values of the parameter $G^{*}$ for the annular zone in a turbulent flow are obtained from Maubach [5] as

$$
G=\frac{3 \cdot 966+1 \cdot 25 x}{1+x}
$$

for smooth walls and in an analogous way as in (7)

$$
\sqrt{\left(\frac{8}{\lambda}\right)}=2 \cdot 5 \ln \frac{L \cdot U^{*}}{v}+5 \cdot 5-G
$$

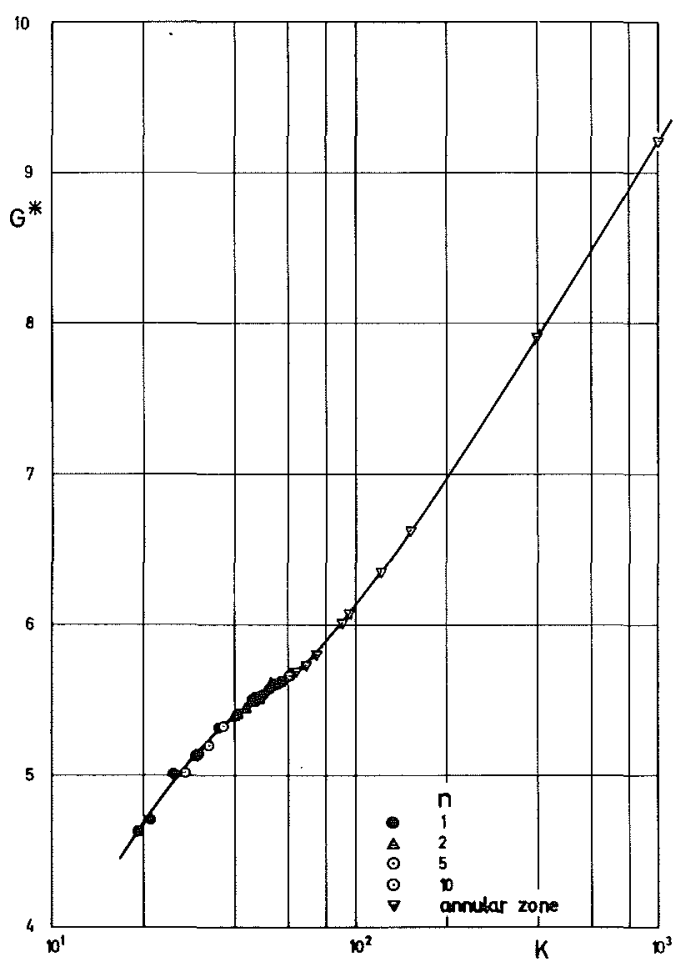

FIG. 3. Geometry parameter $G^{*}$. and with (6) and

$$
\frac{L}{D_{h}}=\frac{\left(r_{0}-r_{z}\right) 2 r_{z}}{\left(r_{0}^{2}-r_{z}^{2}\right) 4}=\frac{1}{2(1+x)}
$$

to be

$$
\begin{aligned}
\sqrt{\left(\frac{8}{\lambda}\right)=2 \cdot 5} & \ln \operatorname{Re} \sqrt{\left(\frac{\lambda}{8}\right)+5 \cdot 5} \\
- & {[G+2 \cdot 5 \ln 2(1+x)] . }
\end{aligned}
$$

A comparison with (18) results in

$$
G_{R Z}^{*}=G+2 \cdot 5 \ln 2(1+x)
$$

and with (28) in

$$
G_{R Z}^{*}=\frac{3.966+1 \cdot 25 x}{1+x}+2.5 \ln 2(1+x) .
$$

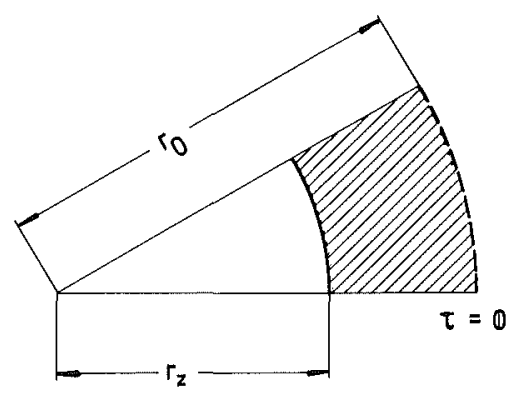

FIG. 4. Annular zonc.

Table 2 lists the values of the geometry factors $K$ and $G^{*}$ for various values of $x$. In addition, it is seen that $A=1$ for annular zones, which is no surprise because there is a constant wall shear stress on the circumference and no subchannels can be generated.

The parameters $A$ in Fig. 5 obtained from the multitube calculation also can be represented in a curve in good approximation which, in this case, is a straight line.

The geometry factors $A$ and $G^{*}$ represented above for turbulent flow in channels can now be used to establish pressure drop relationships also for other geometries, if the geometry parameter $K$ for laminar flow is known.

For a number of flow channels, the laminar 
Table 2. Values of the geometry parameters of the anmular zone in laminar $(\mathrm{K})$ and turbulent $\left(\mathrm{G}^{*}\right)$ flo ws

\begin{tabular}{|c|c|c|}
\hline$\chi$ & $K$ & $G^{*}$ \\
\hline 0 & $64 \cdot 000$ & 5.6988 \\
\hline 0.1 & $64 \cdot 604$ & 5.6902 \\
\hline 0.2 & $66 \cdot 217$ & $5 \cdot 7020$ \\
\hline 0.3 & $68 \cdot 574$ & $5 \cdot 7280$ \\
\hline 0.5 & 74.836 & 5.8072 \\
\hline 0.9 & $91 \cdot 200$ & 6.0170 \\
\hline 1.0 & 96.000 & 6.0737 \\
\hline $1 \cdot 1$ & $100 \cdot 912$ & $6 \cdot 1310$ \\
\hline 1.5 & $122 \cdot 183$ & 6.3600 \\
\hline $2 \cdot 0$ & 152.091 & 6.6327 \\
\hline $5 \cdot 0$ & 393.638 & 7.9149 \\
\hline $10 \cdot 0$ & 993.546 & $9 \cdot 2245$ \\
\hline
\end{tabular}

solution is known from the literature. For triangular shaped ducts, an approximative solution is found with Carlson and Irvine [16], theoretical data are also given by Sparrow [17] and Sparrow and Haji-Sheikh [18]. For eccentric annuli Tiedt [19] has compiled the laminar solutions for all diameter ratios and eccentricities. For rod bundles there are solutions by Sparrow and Loeffler [20] and Sholokhov, Buleev and Gribanov [21] for rod bundles of infinite extension. For rod bundles with seven rods in circular tubes laminar solutions are indicated by Courtaud, Ricque and Martinet [22], Axford [23, 24] and Min, Hoffman, Tucker and Peebles [25]. For rod bundles in hexagonal and square channels, the author has elaborated laminar solutions by numerical integration of Poisson's equation for the subchannels in such rod bundles (centre, wall and corner channels for a wide range of rod distance ratios $P / D$ and wall distance ratios $W / D[15,26]$. With these sub-channel geometry factors, the geometry factors for laminar flow can be calculated in a very simple way for all rod bundles so far investigated experimentally. For ducts with arbitrary cross-section Pendergast, Cobble and Smith [27] reported analytical solutions of Poisson's equation.

The method suggested for calculation of the pressure drop relationships for turbulent flow from the laminar solutions, called the $G^{*}$ method below, can be justified only by saying that the measured results available for various channels with non-circular cross sections are described sufficiently well by the pressure drop relationships obtained in this way.

Influences of anisotropy of the turbulent transport quantities or by secondary flows

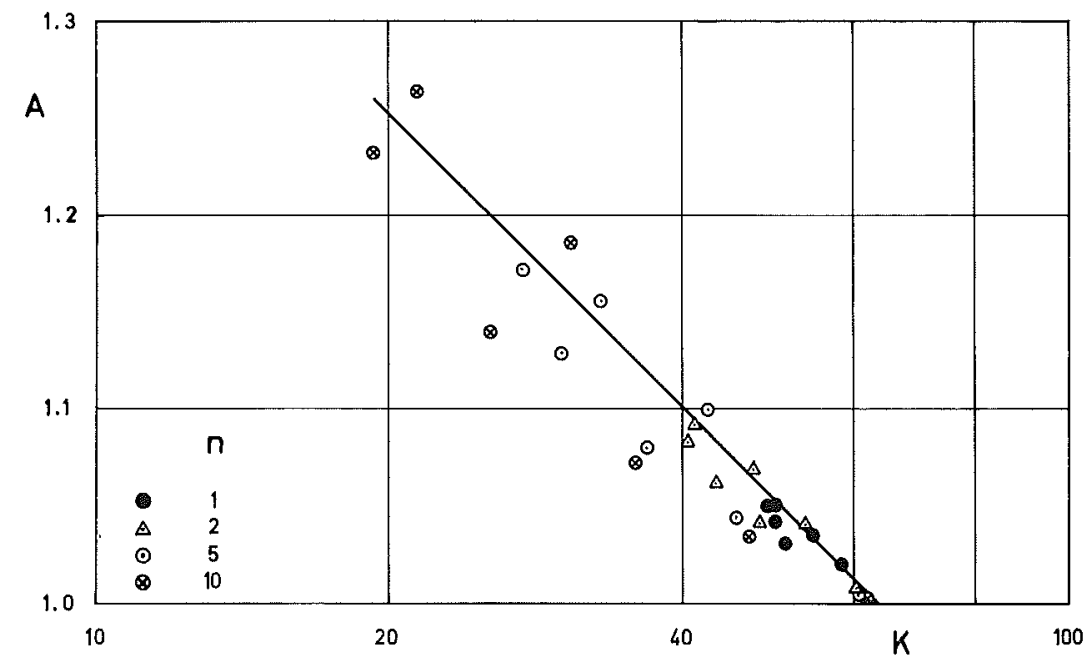

FIG. 5. Geometry parameter $A$. 
observed in non-circular channels of course are not taken into account in a method like this.

In the same way, a momentum exchange between the individual sub-channels of a rod bundle is neglected because the lines for which the momentum transport disappears are selected in the calculations to be the lines resulting if the rods proper and rod and channel wall, respectively, are subdivided at their closest distances.

However, in general these simplifications have but a negligible effect on the friction factors, as has been proved by various authors.

\section{COMPARISON BETWEEN CALCULATED AND AND MEASURED DATA}

The method suggested above will be tested with triangular shaped ducts, eccentric annuli, and rod bundles.

Figure 6 shows the data measured by Carlson [28], which were reported also by Eckert and Irvine [16, 29], obtained from triangular shaped ducts. Agreement between the measured values and the calculated ones is good. For small angles, the transition from laminar to fully developed turbulent flow obviously is not yet complete, hence, the slightly greater deviation.

For eccentric annuli, Fig. 7 contains the data measured by Johnson [30] for a diameter ratio of $d_{1} / d_{2}=0.75$ and $d_{1} / d_{2}=0.281$, respectively. In the case of the lower diameter ratio there is excellent agreement between measured and predicted values; this is not the case for the higher diameter ratio. The data measured by Tiedt [19] show the same behaviour (Fig. 8). For low diameter ratios, again, experiment and theory are in excellent agreement; for high diameter ratios agreement is excellent for the concentric case only. Figure 9 shows the measured data by Bourne, Figueiredo and Charles [31] for a diameter ratio of $d_{1} / d_{2}=0 \cdot 813$ (top). In the turbulent region, the predicted line fits the data excellently, even for a high diameter ratio. Data by Lee [32] are shown in Fig. 9 (bottom) for a diameter ratio of $d_{1} / d_{2}=0.387$. In this case, there would be excellent agreement with the predicted values if all the data were shifted by about 10 per cent, a margin which is necessary also for good agreement between the predicted and the measured values for other

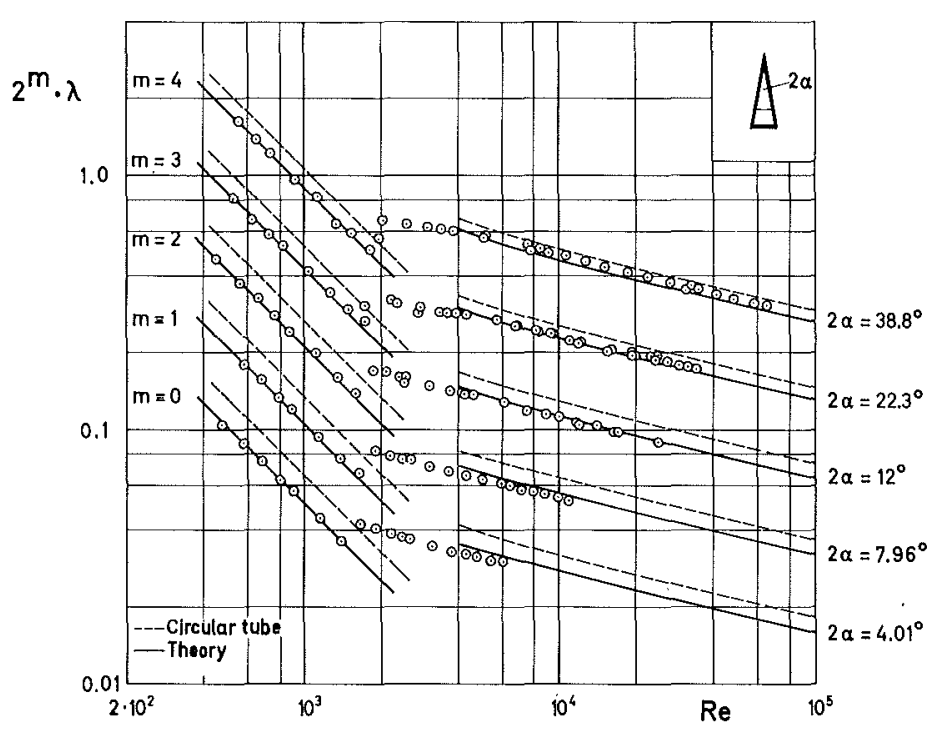

FIG. 6. Triangular shaped duct: Carison. 

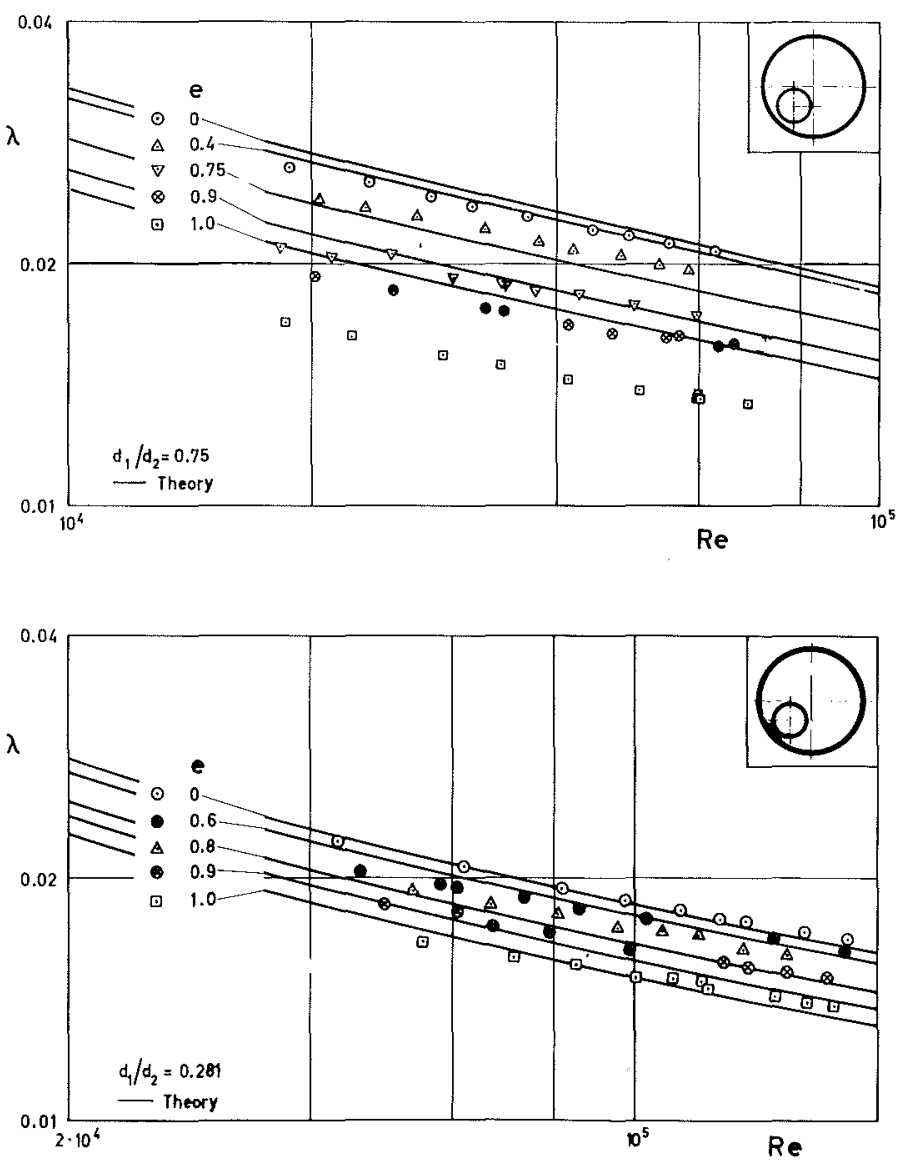

FIG. 7. Eccentric annuli: Jonsson.

diameter ratios tested by Lee and not shown here. The assumption that the data by Lee are too high is reasonable, if one considers the excellent agreement between theory and experiments of different authors in the case of concentric annuli [33].

To illustrate the difference between the predicted values and the measurements for high diameter ratios, Fig. 10 shows all measurements known to the author which are related to the concentric values for maximum eccentricity $(e=1 \cdot 0)$ and different diameter ratios.

The values measured by Jonsson [30] and Tiedt [19] are the lowest for high diameter ratios; they are correlated rather well - especially with respect to the dependence on the diameter ratio-by the calculations of Eifler and Nijsing [34]. The experimental results of Bourne et al. [31], Lee [32], Denton [35], and Dodge [36] are higher and well correlated by the method suggested above. It is impossible to decide at this time which experimental values are best, even in the light of the data measured by Diskind [37] for eccentricities between $e=0.9$ and $e=0.97$ tending to the higher values, and the investigation of Stampa [38] who reported "the influence of eccentricity measured by Tiedt could not be verified by our experimental studies".

Now for the rod bundles. For seven rods in a 

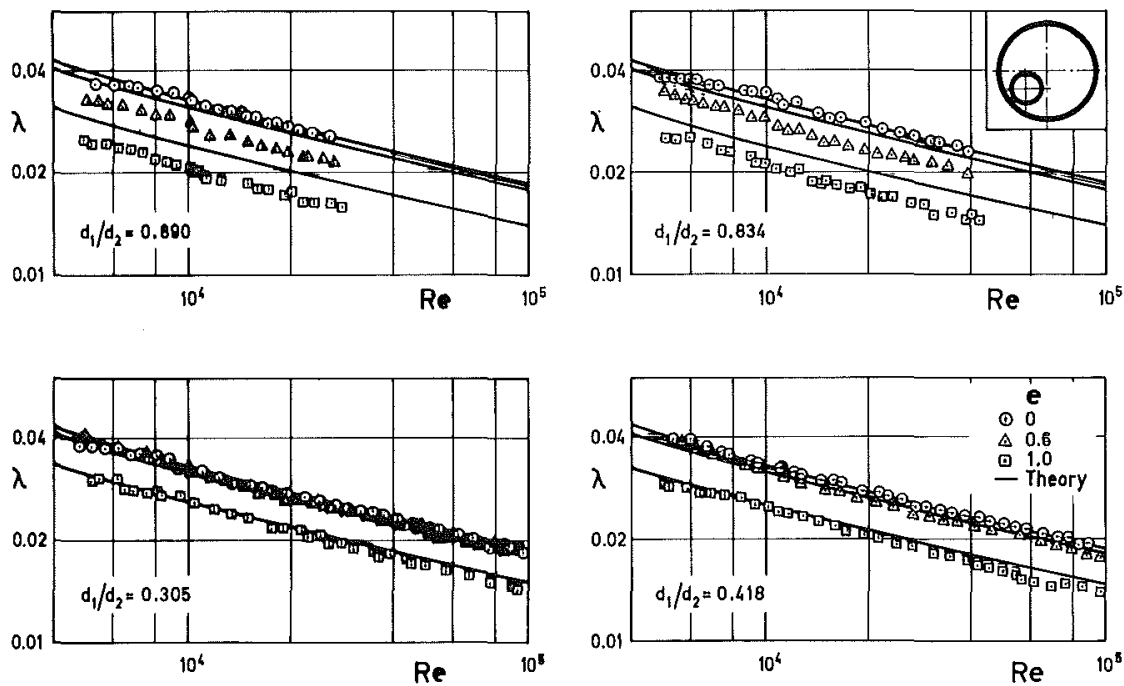

FIG. 8. Eccentric annuli: Tiedt.
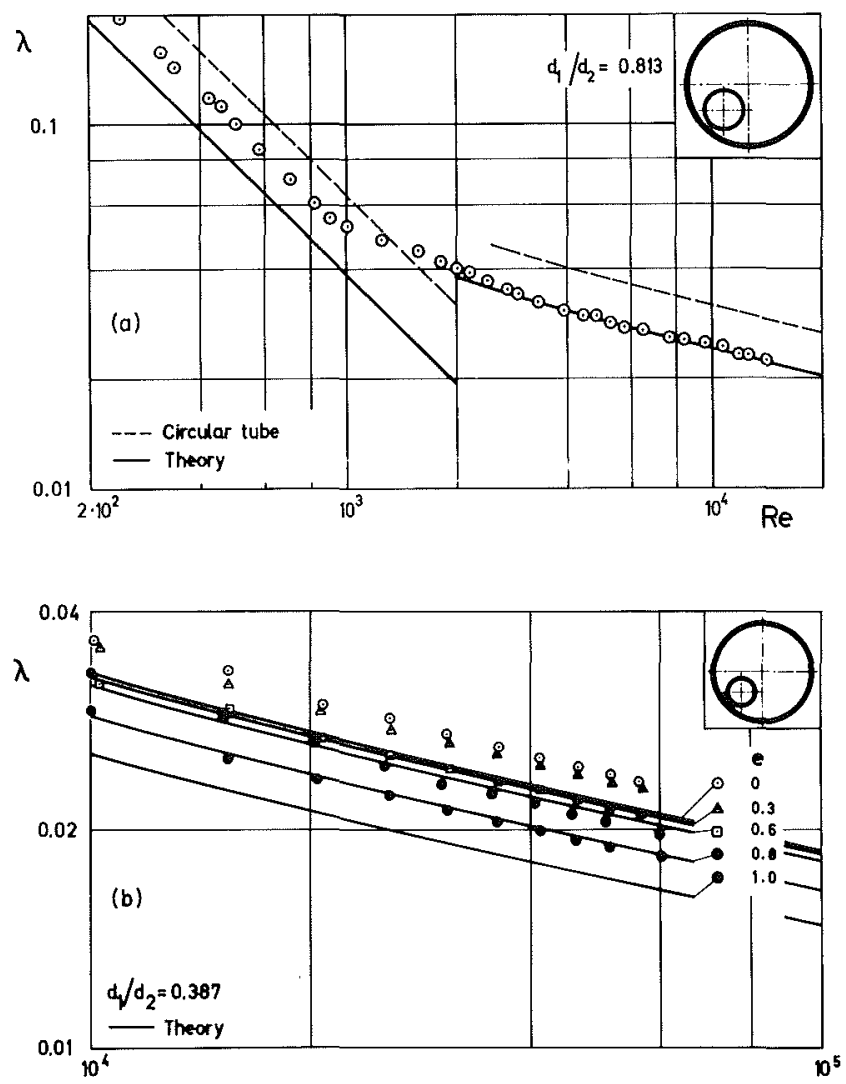

Fig. 9. Eccentric annuli. 


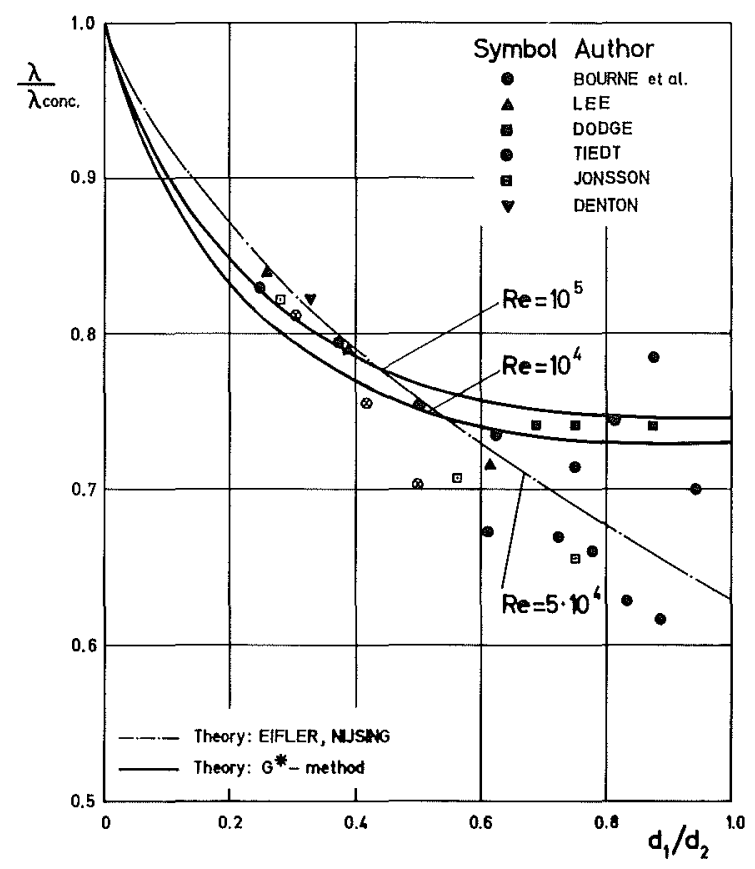

FIG. 10. Eccentric annuli: $e=1 \cdot 0$.

circular tube Courtaud et al. [22] performed experiments with a large number of rod distances. The results are shown in Fig. 11. Except for the extreme position, in which the rods contact each other, there is excellent agreement between the calculated and the experimental data. The same applies to the studies conducted by the author on rod bundles in hexagonal channels with rod distance ratios $P / D$ equal to the wall distance ratios $W / D[39,40]$ for different rod distance ratios and rod numbers, as is shown in Figs. 12-14. Also for other wall distances there is good agreement between experiment and theory. This is shown by the measured data of Galloway and Epstein [41, 42] for 19-rod bundles with half the rod distance as the wall distance (Fig. 15). The results measured by Gunn and Darling $[1,43]$ for rod bundles in a square array could well be described also by the curve determined by the $G^{*}$-method (Fig. 16). The excellent description of the experimental results by the theoretical method is shown especially

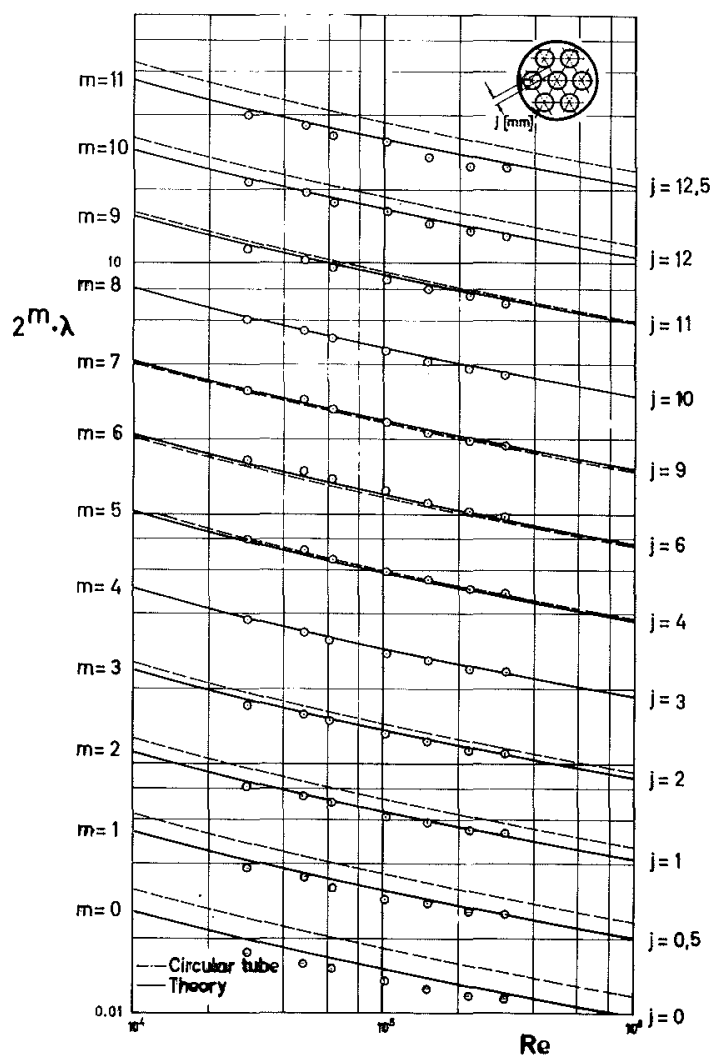

FIG. 11. Rod bundles : Courtaud et al.

by extreme shapes of channels such as those occurring for rod bundles with $P / D=1$ and $W / D=1$, respectively.

For the square array, Gunn and Darling $[1,43]$ have performed measurements on one centre, side and corner channel each. Figure 17 shows the results. Agreement with calculated data is good. The theoretical geometry factors for laminar flow [15] were used for calculation. The values measured in the laminar area are slightly higher than the theoretical solution. The agreement would be perfect if the values measured by Darling were used for $K$. For $P / D=1$ in a square array, measured results have been communicated also by Ushakov et al. [44]. Agreement is good (Fig. 18).

For $P / D=1$ in a hexagonal pin array, Fig. 19 


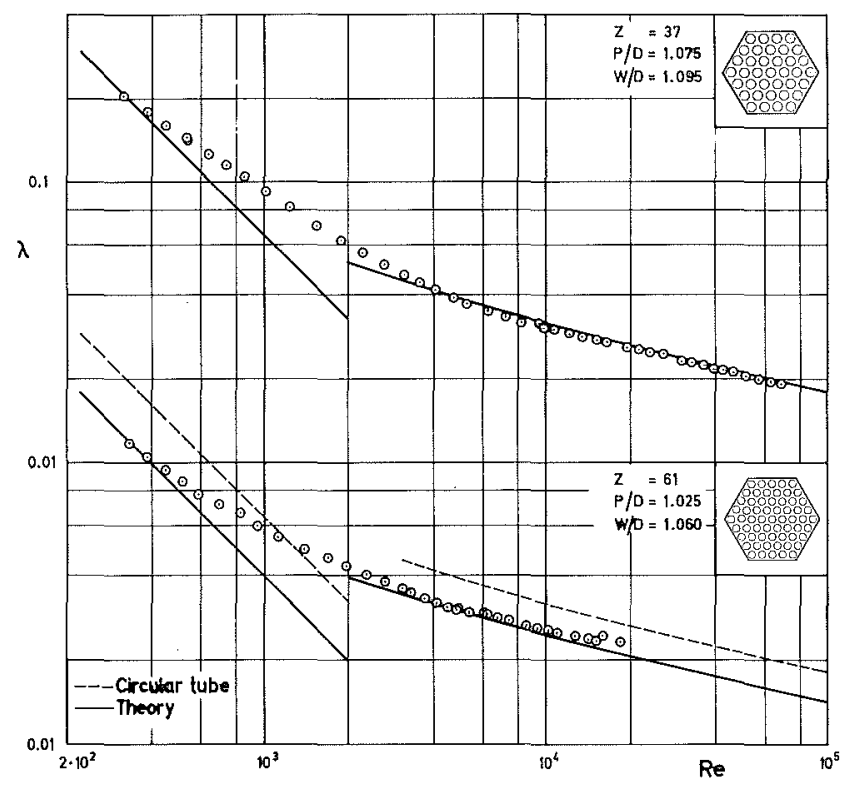

FIG. 12. Rod bundles: Author.

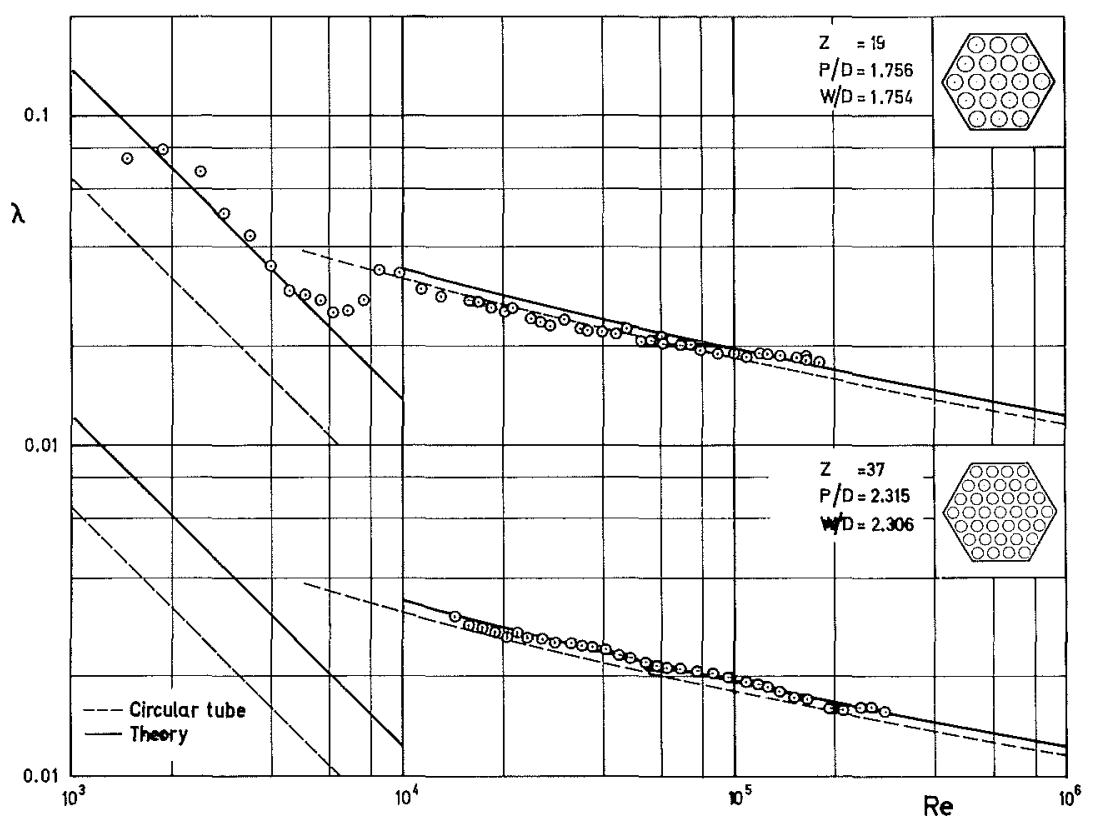

FIG. 13. Rod bundles: Author. 


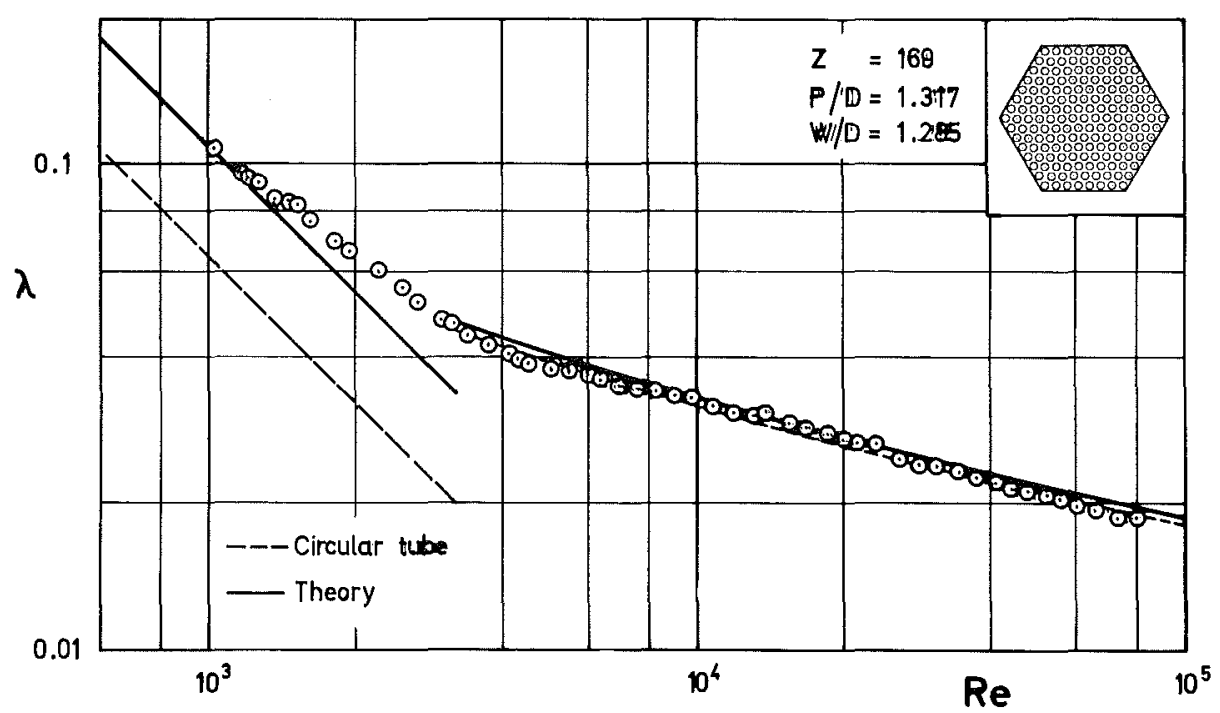

FIG. 14. Rod bundles: Author.

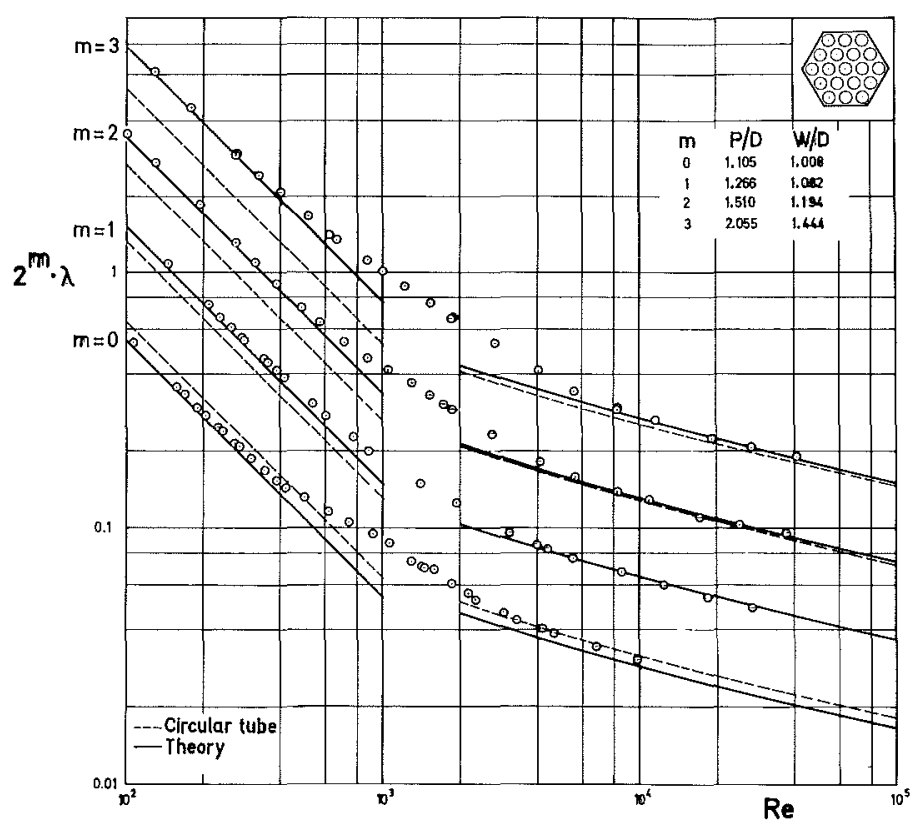

FIG. 15. Rod bundles: Galloway. 


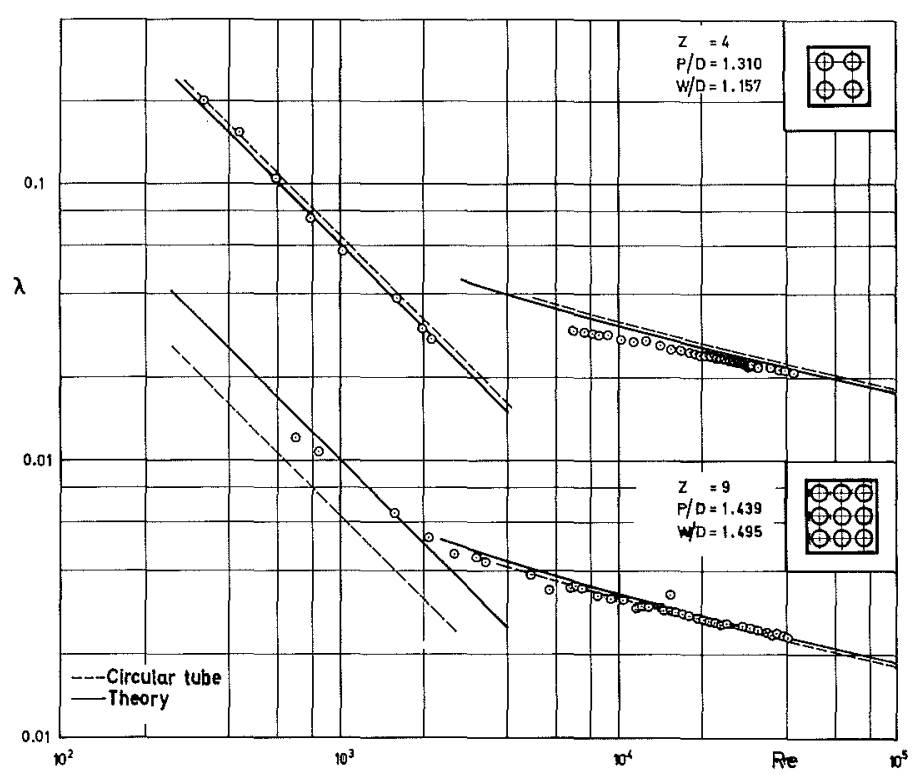

FIG. 16. Rod bundles: Gunn and Darling.

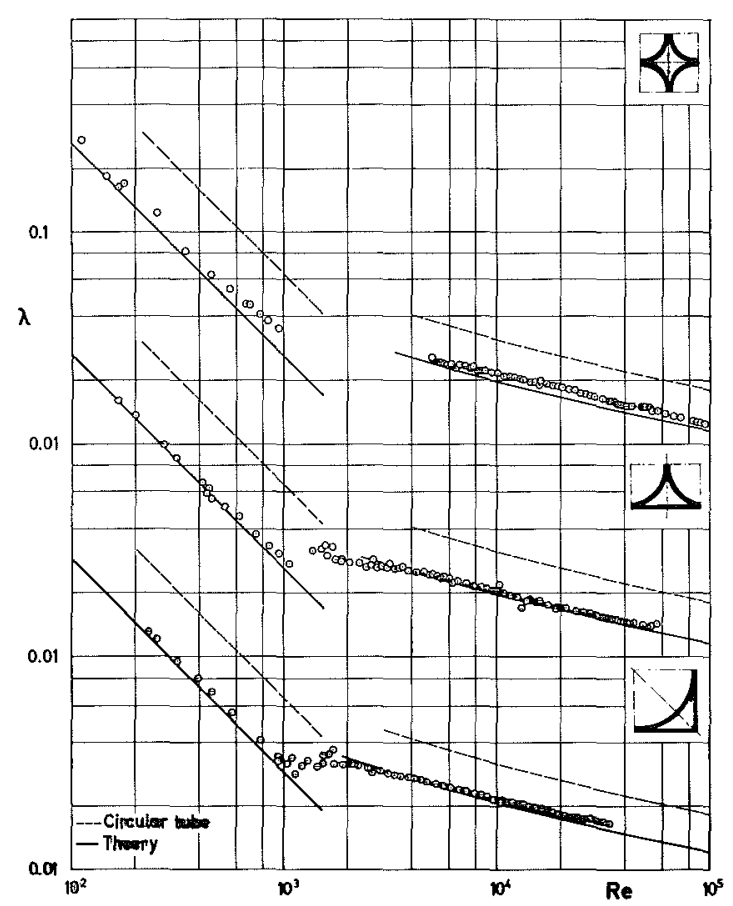

FIG. 17. Rod bundles: Darling. 


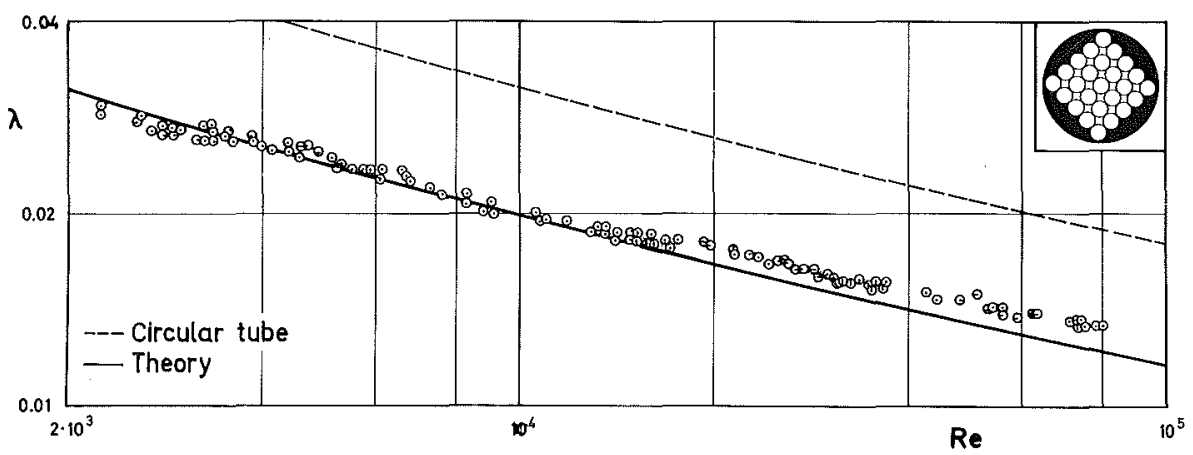

FIG. 18. Rod bundles: Ushakov et al.

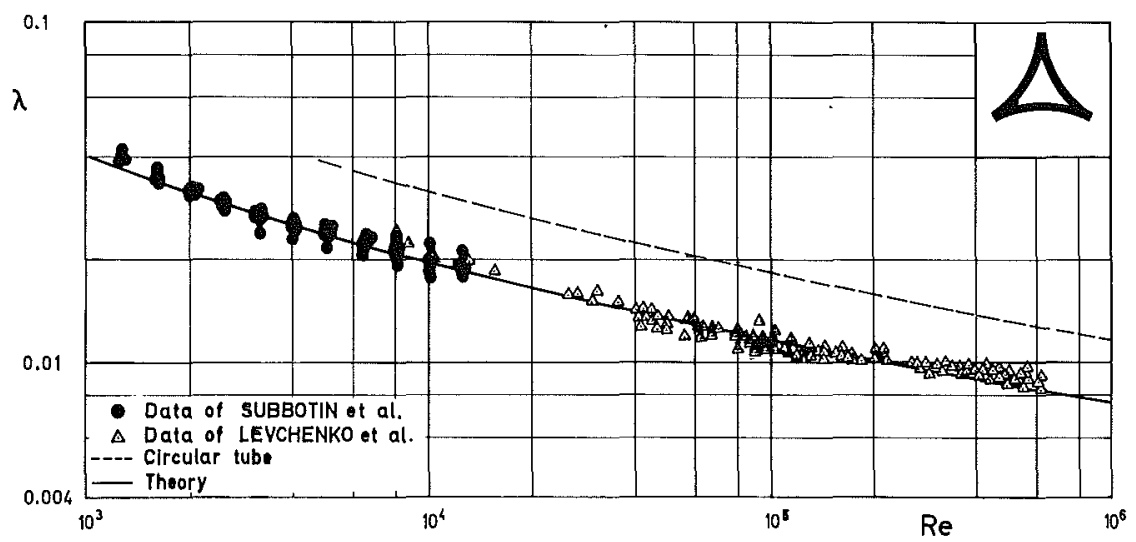

FIG. 19. Rod bundles.

shows the results measured by Subbotin et al. [45], and Levcheko et al. [8]. All measured values are excellently described by the curve of the friction factor by the $G^{*}$-method.

\section{CONCLUSIONS}

In summary it can be said that the friction factors calculated by the method outlined for turbulent flow in channels with non-circular cross sections very "well describe the experimental data at hand.

The method is very simple because it requires only knowledge of the geometry factor for laminar flow, which is a condition that can be fulfilled as a rule for the channels occurring in practice.

In that case, the geometry factors $A$ and $G^{*}$ can be taken from two diagrams in which the pressure drop relationship

$$
\sqrt{\left(\frac{8}{\lambda}\right)}=A\left[2 \cdot 5 \ln R e \sqrt{\left.\left(\frac{\lambda}{8}\right)+5 \cdot 5\right]-G^{*}}\right.
$$

for turbulent flow is determined.

Because of its easy application and yet high accuracy, this method of calculation of friction factors in turbulent flows is superior to all the methods of calculation previously suggested. Hence, it can be used also for other, shapes of 
channels to predict friction factors for turbulent flow with sufficient accuracy and in a simple way.

\section{ACKNOWLEDGEMENTS}

The author wishes to express his gratitude to Dr. K. Maubach for numerous useful discussions and to $\mathrm{Mr}$. A. Roth for the careful preparation of the diagrams.

\section{REFERENCES}

1. D. J. Gunn and C. W. W. Darling, Fluid flow and energy losses in non-circular conduits, Trans. Instn Chem. Engrs 41, 163-173 (1963).

2. V. S. OsmachKin, Some problems of heat transfer in liquid cooled reactors A/Conf. 28/P/326 UdSSR (1964) Third United Nations International Conf. on the Peaceful Uses of Atomic Energy.

3. YU. P. Shlykov and S. N. TsarevskiI-Dyakin, Turbulent flow and heat exchange in smooth straight channels of any cross-section, Thermal Engineering 13 (12), 90-96 (1966).

4. E. ARANOvitch, A method for the determination of the local turbulent friction factor and heat transfer coefficient in generalized geometries, $J$. Heat Transfer 93, 61-68 (1971).

5. K. MAUBACH, Reibungsgesetze turbulenter Strömungen Chemie-Ing. Technik 42 (15), 995-1004 (1970).

6. J. NikuradSE, Gesetzmässigkeiten der turbulenten Strömung in glatten Rohren, Forsch.-Arb.-Ing.-Wesen, VDI-Forschungsheft No. 356 (1932)

7. W. Eifler and R. Nissing, Fundamental studies of fluid flow and heat transfer in fuel element geometries. Pt II. Experimental investigation of velocity distribution and flow resistance in a triangular array of parallel rods, Report EUR 2193 e of the European Atomic Energy Community (1965); Nucl. Engng Design 5, 22-42 (1967).

8. Yu. D. Levchenko, V. I. Subbotin, P. A. Ushakov and A. V. SHEYNINA, Geschwindigkeitsverteilung in der Zelle eines dicht gepackten Stabbündels, Liquid Metals, pp. 223-34. Atomizdat, Moskau (1967); cf. KFK-tr-371.

9. Yu. D. Levchenko, V. I. Subbotin and P. A. Ushakov, The distribution of coolant velocity and wall stresses in closely packed rods, Atomnaya Energiya 22 (3), 262 (1968).

10. M. Kh. Ibragimov, I. A. Isupov and V. I. Subbotin, Calculation and experimental study of velocity fields in a complicated channel, Liquid Metals, pp. 234-250. Atomizdat, Moscow (1967); cf. KFK-tr-379 (1971).

11. V. I. Subbotin, P. A. Ushakov, Yu. D. Levchenko and A. M. Aleksandrov, Velocity fields in turbulent flow past rod bundles, Heat Transfer-Soviet Research 3 (2), 9-35 (1971).

12. J. A. Brighton and J. B. Jones, Fully developed turbulent flow in annuli, $J$, Basic Engng 86D, 835-844 (1964).

13. A. QuARMBY, An experimental study of turbulent flow through concentric annuli, Int. J. Mech. Sci. 9, 205-221 (1967).
14. K. Maubach and K. ReHme, Negative eddy diffusivities for asymmetric turbulent velocity profiles? Int. J. Heat Mass Transfer 15, 425-432 (1972).

15. K. ReHme, Laminarströmung in Stabbündeln, ChemieIng.-Technik 43, 962-966 (1971).

16. L, W. Carlson and T. F. IRvine JR., Fully developed pressure drop in triangular shaped ducts. J. Heat Transfer 83C, 441-444 (1961).

17. E. M. SPARRow, Laminar flow in isosceles triangular ducts, A.I.Ch.E. Jl 8 (5), 599-604 (1962).

18. E. M. Sparrow and A. HAJI-ShfikH, Laminar heat transfer and pressure drop in isosceles triangular, right triangular, and circular sector ducts, $J$. Heat Transfer 87, 426-428 (1965).

19. W. TIEDT, Berechnung des laminaren und turbulenten Reibungswiderstandes konzentrischer und exzentrischer Ringspalte, Chemiker-Ztg./Chem. Apparatur 90, 813-821 (1966); 91, 17-25, 149-155, 299-311, 569576, 968-975 (1967); 92, 76-89 (1968).

20. E. M. SPARrow and A. L. LoEFFLER, Longitudinal laminar flow between cylinders arranged in regular array, A.T.Ch.E. Jl 5, 325-330 (1959).

21. A. A. Sholokov, N. I. Buleev, Yu. I. Gribanov and V. E. Minashin, Longitudinal laminar fluid flow in a bundle of rods, Inz. Fiz. Zh. 14 (3), 389-394 (1968) (in Russian).

22. M. Courtaud, R. Ricque and B. Martinet, Etude des pertes de charge dans des conduites circulaires contenant un faisceau de barreaux, Chem. Engng Sci. 21, 881-893 (1966).

23. R. A. AXFORD, Longitudinal laminar flow of an incompressible fluid in finite tube bundles with $m+1$ tubes, Report LA-3418, Los Alamos Scientific Laboratory (1966).

24. R. A. Axford, Summary of theoretical aspects of heat transfer performance in clustered rod geometries, Report LA-DC-9786, Los Alamos Scientific Laboratory (1968).

25. T. C. Min, H. W. Hoffmann, T. C. Tucker and F. N. PeEbles, An analysis of axial flow through a circular channel containing rod clusters, W. A. SHAw, Developments in Theoretical and Applied Mechanics, Bd. 3, p. 667. Pergamon Press, Oxford (1967).

26. K. REHME, Laminarströmung in Stabbündeln, Paper presented at the 1971 Reaktortagung des Deutschen Atomforums, Bonn, March 30-April 2, pp. 130-133 (1971).

27. D. Pendergast, M. Cobble and P. SMith, Laminar flow through ducts of arbitrary cross-section, Int. $J$. Mech. Sci. 12, 695-703 (1970).

28. L. W. CARLSON, Experimental friction factors for fully developed turbulent flow in smooth triangular ducts, MS thesis, Mechanical Engineering Dept., University of Minnesota, Minneapolis (1959).

29. E. R. G. Eckert and T. F. IRvine, JR, Pressure drop and heat transfer in a duct with triangular cross section, J. Heat Transfer 82C, 125-138 (1960).

30. V. K. Jonsson, Experimental studies of turbulent flow phenomena in eccentric annuli, Ph.D. Thesis, University of Minnesota, Minneapolis (1965).

31. D. E. Bourne, D. Ftguetredo and M. E. Charles, 
Laminar and turbulent flow in annuli of unit eccentricity, Can. J. Chem. Engng 46, 289-293 (1968).

32. Y. LEE, Turbulent flow and heat transfer in concentric and eccentric annuli, Ph.D.Thesis, University of Liverpool (1964).

33. W. EIFLER, UUber die turbulente Geschwindigkeitsverteilung und Wandreibung in Strömungskanälen verschiedener Querschnitte, Dissertation Technische Hochschule Darmstadt (1968).

34. W. EIFLeR and R. NiJsing, Berechnung der turbulenten Geschwindigkeitsverteilung und Wandreibung in exzentrischen Ringspalten, ATKE 18 (2), 133-142 (1971).

35. J. D. Denton, Turbulent flow in concentric and eccentric annuli, University of British Columbia, MS Thesis (1963).

36. N. A. Dodge, Friction losses in annular flow, ASME paper No. 63-WA-11 (1963).

37. T. Diskind, Heat transfer and pressure drop in eccentric annuli, Report NYO-9649 of Columbia Univ., Department of Chemical Eng., New York (1961).

38. B. Stampa, Experimentelle Untersuchung an axial durchströmten Ringspalten, Ph.D.Thesis, University of Braunschweig, Germany, Pfleiderer-Institut für Strömungsmaschinen (1971).
39. K. Rehme, Pressure drop performance of rod bundles in hexagonal arrangements, Int. J. Heat Mass Transfer 15, 2499 (1972)

40. K. ReHmE, Widerstandsbeiwerte von Gitterabstandshaltern für Reaktorbrennelemente, $A T K E \quad 15$ (2), 127-130 (1970).

41. L. R. Galloway and N. Epstein, Longitudinal flow between cylinders in square and triangular arrays and in a tube with square-edged entrance, A.I.Ch.E.-I. Chem. E. Symposium Series No. 6, London (1965).

42. L. R. Galloway, Longitudinal flow between cylinders in square and triangular arrays, University of British Columbia, Ph.D.Thesis (1964).

43. C. W. W. Darling, Fluid flow and energy losses in irregular conduits of constant flow area, M.Sc.Thesis, Department of Chemical Engineering, Queen's University Kingston, Ontario (1961).

44. P. A. Ushakov, V. I. Subbotin, B. N. Gabrianovich, V. D. TALANOV and I. P. SviridenKo, Heat transfer and hydraulic resistance in tightly packed corridor bundle of rods, Atomnaya Energiya 13 (2), 162-169 (1962).

45. V. I. Subbotin, P. A. Ushakov and B. N. GabrianovICH, Hydraulischer Widerstand bei durch Flüssigkeiten längsumströmten Stabbündeln, Kernenergie 4, 658-660 (1961); cf. Atomnaya Energiya 9, 308, (1960).

\section{METHODE SIMPLE DE CALCUL DES FACTEURS DE FROTTEMENT POUR L'ECOULEMENT TURBULENT DANS DES CANAUX NON-CIRCULAIRES}

Résumé - A l'aide des lois régissant la perte de charge dans un modèle simple une méthode est mise au point qui permet de calculer le coefficient de perte de charge d'un écoulement turbulent dans les canaux non-circulaires, supposant seulement la connaissance du facteur de géométrie de la loi régissant la perte de charge de l'écoulement laminaire. La méthode de calcul proposée est vérifiée sur de nombreux résultats expérimentaux dérives de la littérature et portant sur des canaux non-circulaires, p.ex. des triangles acutangles, des fentes annulaires excentriques et des faisceaux de barres disposés de façon hexagonale et carrée dans des tubes circulaires et des canaux hexagonaux et carrés. Il apparait que l'ensemble du matériel expérimental peut être très bien décrit à l'aide de la méthode mise au point.

\section{EINFACHE METHODE ZUR BESTIMMUNG VON REIBUNGSKOEFFIZIENTEN FÜR TURBULENTE STRÖMUNG IN NICHT-KREISFÖRMIGEN KANÄLEN}

Zusammenfassung-Anhand der Druckverlustgesetzmässigkeiten eines einfachen Modells wird eine Berechnungsmethode für den Druckverlustbeiwert bei turbulenter Strömung in nicht-kreisförmigen Kanälen entwickelt, wobei nur die Kenntnis des Geometriefaktors des Druckverlustgesetzes für die laminare Strömung vorausgesetzt wird. An zahlreichen Versuchsergebnissen aus der Literatur bezüglich nicht-kreisförmiger Kanäle wie spitzwinklige Dreiecke, exzentrische Ringspalte und Stabbündel in hexagonaler und quadratischer Anordnung in Kreisrohren, Sechskant- und Vierkantkanälen wird das vorgeschlagene Berechnungsverfahren geprüft. Es zeigt sich, dass das gesamte Versuchsmaterial mit dem entwickelten Verfahren sehr gut beschrieben werden kann. 


\section{ПРОСТОЙ МЕТОД РАСЧЕТА КОЭФФИЦИЕНТОВ ТРЕНИЯ ТУРБУЛЕНТНОГО ТЕЧЕНИЯ В НЕКРУГЛЫХ КАНАЛАХ}

Аннотация-На основе закономерностей гидравлического сопротивления иростого моделя разработан метод вычисления коэффициента гидравлического сопротивления при турбулентном потоке жидкости в некруглых каналах, причем предполагается только знание геометрического фактора закона гидравлического сопротивления для ламинарного потока. Предлагаемый метод расчета проверен с помощью многочисленных әкспериментальных данных в литературе относительно таних некруглых каналов, как : остроугольные треугольники, эксцентричные кольцевые зазоры и иучки стержней с шестиугольной и квадратной решеткой в круглых трубах и каналах четырехугольного и шестиугольного сечений. Оказывается, что весь әкспериментальный материал очень хорошо описывается путем әтого разработанного метода. 